\title{
The Importance of Digital Marketing on the Success of Service Companies in the Kingdom of Saudi Arabia
}

\author{
Dr. Ali Rashed Nasr \\ Doctorate of Sales and Marketing, University of Calgary, Alberta, Canada \\ Email: $\underline{\text { ali.naser@yahoo.com }}$
}

\begin{abstract}
The study aims to shed light on digital marketing, its value, economic advantages, and criteria for its growth in the Kingdom of Saudi Arabia. The globalization of the digital marketing industry, its pace of growth, and its simplicity have contributed to the appetite of customers, which called for the ease of its development, attention, and analysis of this phenomenon. In addition to improving the means of protection in them, using them to achieve economic benefits, improving dealing with them, and establishing laws to increase consumer confidence in the Kingdom of Saudi Arabia. There is no doubt that there are many problems in the practice of digital marketing, such as economic, marketing, customs, and legal challenges that need support from the relevant government departments, especially concerning information security, electronic payment methods, and others.
\end{abstract}

Keywords: digital marketing, economic benefits, consumer 


\section{Introduction}

The rapid transformation of information technology has led to a major shift in the patterns of economic interaction through which the means of communication can distribute information, resources, capital, and goods. The so-called digital marketing has emerged as the current and most important paradigm change in the field of trade and industry, and with the spread of a modern global economic system that focuses on globalization and liberalization of trade in goods and services, and with the removal of customs borders and prohibitions, digital marketing has emerged dramatically and the number of consumers has increased. The seller and the customer are at the end of the trading arrangement.

Global web companies (www) (known as "dot. Com companies" were doing business with people across websites, multiplying amazingly, spreading their heads in both corners, and unexpectedly crashing into stock markets. He has modified the way purchases are made in regions. The different market, whether through finding modern outlets that produce large profits, or through the ability to access a new form of customers, or through controlling the supply chain of business. $^{1}$

Online transactions have become the preferred business practice of many companies and a large number of individuals in the United States of America. In particular, computers, consumable office supplies, buying existing, recycled books and old records, subscribing to magazines, periodicals, and newspapers, as well as travel plans.

Likewise, the sale of ticket reservations, the auctioning of rooms, the rental of vehicles on collectibles, appliances, and second-hand goods, and the increase in direct sales at an incredible price that the new commercial industry has not seen before. Both the creative and enterprising pioneers, seizing any opportunity, and thriving traditional businesses - also called mortar-and-brick enterprises (because

\footnotetext{
${ }^{1}$ Reynolds, J., The Complete E-Commerce Book: Design, Build, and Maintain a Successful WebBased Business, CMP Books (April 2004).
} 
they make bricks and stones) - know that digital marketing is, and still is, an open market without a roof. A golden opportunity for companies whose return on investment doubles day after day.

Thus, digital marketing has moved (Electronic Commerce) or (-e-commerce) from adventures in the commercial market to an integral part of the commercial market open to competition.

\subsection{Study questions:}

What is the definition of digital marketing?

What are the advantages of digital marketing?

What are the requirements for developing digital marketing in the Kingdom of Saudi Arabia?

\subsection{Study aims:}

Researching or delving into any topic aims to achieve many purposes, such as revealing rights, clarifying ambiguities, or confirming facts. We are conducting this study to achieve a set of goals represented in:

- Learn about information and communication technologies, and explain their impact on the commercial field

Learn about the modern phenomenon that has spread rapidly around the world, which is digital marketing.

- Clarifying the picture related to the status of digital marketing in the world in general and the Arab world in particular, and reviewing some efforts to rehabilitate societies to become able to deal with digital marketing, to draw lessons from the experience of success.

- Shedding light on the reality of digital marketing in the Kingdom of Saudi Arabia, and uncovering the most important challenges and obstacles that prevent its development. 
- Show some ways to promote this modern and commercial activity in the Kingdom of Saudi Arabia

\subsection{Study importance}

This research derives its importance from the importance of the topic dealt with in dealing with the phenomena of digital marketing, which are characteristics of the information economy. One of the most important contributions of technology and the information revolution to today's economy. Many thinkers and businessmen posed this question, and many studies and discussions about it are still ongoing, especially at the level of regional and international bodies and organizations. This is due to its general importance, as it is one of the most important pathways for economic growth. Digital marketing plays an important role in developing countries economic development, increasing their international trade and promoting multiple local industries. Qualifying institutions to enter the world of globalization and ensuring their survival and ability to compete, as well as opening the doors for individuals to integrate into the new economy and test the online shopping process.

\subsection{Study terms}

\section{Knowledge economy:}

It is a modern economy of a peculiar nature, and it derives its peculiarity not only from the concerns of the present and the past but also from the role it will play in the future ... The knowledge economy can also be described as "a set of focused and tested information serving a specific topic. In a way, by gathering this information and its characteristics, we gain advanced experience in a specific topic, and from here, the structures based on knowledge bases arose.

\section{Digital economy:}

It is used to refer to the Internet-centered economy and can be defined as the term

" digital economy", the economy based on information and communication technology, the degree of connection to the global information network ((Internet)), 
The availability of high-speed information methods, mobile phones, and information-sharing facilities. Digital, the foundations that govern all aspects of the Internet. ".

\section{Digital Marketing:}

It is "the exchange of goods and services through electronic means or mechanical means", and the Internet is often an electronic medium that provides a free public network. Whereas the World Trade Organization describes digital marketing on a broader scale and principle, such as that "digital marketing includes the practices of manufacturing, distribution, marketing, selling, or providing products and services to the buyer via electronic media." This scope is not limited to digital marketing for the purchase of a single commodity, but rather includes any services or information.

\section{Previous studies}

The first study: a study of the trend of business sectors towards digital marketing in the Kingdom of Saudi Arabia, August 2019

The second study: a study of digital marketing, its truth and facts in Algeria 2010/2011

The third study: Digital Marketing and job opportunities for female graduates in the Kingdom, King Abdulaziz University, Center for Strategic Studies 2010, and the study dealt with the following elements:

The foundations for successful digital marketing

Women and digital marketing

Digital marketing and making the field of work available to Saudi women.

\section{Lecture review:}

\subsection{Advantages of digital marketing}

There are many advantages of digital marketing, some of which are called benefits that are in line with contemporary life, and some are unparalleled in consumer 
culture. Any of them falls in the context of enhancing access to live's comforts, including privilege, greed, and misuse of money, as they are synonymous with advertisements and temptations that persecute people, both on the web and via electronic surplus. Most people pay for what they don't use and don't have any need. It is like any form of media and communication, and like every new technology, it has good points and risks, although many agree that the many benefits of e-commerce outweigh its harms and evils, which should be paid with caution.

\section{- Creating more specialized markets}

Digital marketing can include the possibility of developing more niche markets in a way that cannot be achieved through traditional business practices, as it is possible, for example, to create a platform that offers a specific form of product, building material, food, or machine tool.

\section{- The cost of communication is lower}

The Internet is a very inexpensive means of communication compared to traditional means of communication, such as telephone and fax, and it often saves time and effort, for example by sending an e-mail to several people at the same time. Life moment.

\section{- Commercial means that keep up with the times}

In the age of information and intelligence, anyone with access to the Internet spends several hours in front of a screen, whether at home, as adults search for information through browsers and study what is happening, or just floating surfing without a specific goal to meet the motives of curiosity, and where young people learn or prefer to practice Sports, or at Internet Café Net for a chat. They are both walking with a small screen in front of them and ready to receive promotional campaigns on the new computer and Internet-related goods, such as services, games, methods that speed up Internet browsing, and various means of display. This is in addition to the many glamorous personal purchases, as well as other merchandise that haunts consumer advertisements everywhere they go: on 
television websites, newspapers, magazines, home mail, radio, billboards along the highways, and slow roads ... instead, all the advertising media advertising on The website of the product or manufacturer on the Web, to encourage those who missed a quick or concise advertisement to explore the Internet.

Those who are isolated from the modern digital world are not excluded from advertising campaigns for e-commerce, some see ads, and those who deal with them from children, relatives, and friends who happen to see what he saw, heard, or narrated about his experience with the color of modern commerce.

\section{- Globalization of the market}

Digital marketing has acquired a global character that does not recognize borders and transcends the boundaries of traditional commercial markets, and thanks to it, the world has turned into an open market for the consumer, regardless of the geographical location of the seller or buyer. And if the GATT (The General Agreement on Trade and Tariffs) or other international agreements seeks to liberalize trade in goods and services, then digital marketing by its nature achieves this goal without the need for rounds of negotiations, as it is not subject to any restrictions.

\section{- Benefits to governments}

The benefits to governments of digital marketing include the following: ${ }^{2}$

- Reducing the costs of obtaining requirements and services and shortening the period of obtaining them (bids, offers, and bids are submitted quickly, which allows the speed to meet requirements.

- Low prices for goods and services (the electronic company's operating costs are lower than the traditional company.

- $\quad$ increase in the list of good suppliers

- Expansion of the buyer's production

- Better information management.

${ }^{2}$ SBA OfficeofAdvocacy, E-Commerce Report, U.S. Small Business Administration; (July 1999) 
- A better way to control inventory count (all quantities and orders are recorded electronically including sources and departments that acquire purchases or services.

\subsection{Digital Marketing Requirements}

For Internet commerce to become available in any society, it is necessary to provide the appropriate environment for it, as well as the requirements for its fulfillment

\section{- Infrastructure}

Infrastructure includes the elements that enable digital marketing and commercial transactions over the Internet. The information and communication technology industry, which includes telecommunications networks, communication devices such as faxes and fixed and mobile phones, as well as computers, software, drivers, technical support facilities, and personnel, is one of the most influential components of this. Building. Capital to be used in industry and online marketing, in addition to supplying IT output industries. These components include an electronic infrastructure that helps widespread use of the Internet and provides an atmosphere for the leader to engage in appropriate e-commerce. The spread of the Internet is an electronic aspect because it is an electronic medium or an electronic marketplace in which transactions and commercial exchanges take place.

The spread of the Internet often depends on the availability of basic components, including the availability of personal computers, phones, and host computers, and the ability to access the Internet through knowing the number of customers, customers, and future users of the Internet.

\section{- Legislation and regulations}

Legislation, laws, and rules consistent with the nature of online commerce are the legal and regulatory framework that ensures the continuation of digital marketing and the protection of the rights of the parties that deal with it. 
This legal framework also guarantees the establishment of appropriate legal tools for electronic transactions, such as means of contracting via the Internet or e-mail, and the necessary conditions for this, and the settlement of electronic commercial disputes, whether within the community or between the parties in different countries, as well as dealing with the means of evidence for the parties in conflict commercially through the Internet. These legislations also included issues related to intellectual property rights, electronic crimes, defining the concept of harm and harm resulting from those crimes, dealing with electronic signatures, and what is the form of electronic offer and acceptance. Digital marketing, whether direct or indirect, takes place at the level of one or several layers above the real infrastructure and includes any range of unique activities related to the requirements and demands of a specific customer or group of users, such as direct business activities, and direct sources of information. Thus, the Internet and the digital marketing emerging from it have given rise to clear new challenges in business and law. The dot com companies have defied traditional business models, and that may be the reason for their collapse. Digital marketing directly or indirectly challenges the legal and regulatory frameworks in their original places, and the repercussions of this challenge appeared in Europe, where it began to appear in other regions of the world

While part of the solution to these challenges was technical, most of it lies with the private sector, and some of them include special legislation at the local and global level so that e-commerce can continue to develop and be used without hindrance. Digital marketing issues are global and have legal ramifications that include:

- Verification: Verification includes verification of the identity of users, for example signature and authentication.

- Privacy and data protection: protecting people from using private data, and the freedom to transfer that personal data, including name, address, etc.

Liability for illegal actions, including website content and merchandise sold Computer Crime. 


\section{- Privacy and data protection}

Collecting, using, and transferring data that refer to a person, such as collecting data from websites about customers, users, and employees, using it for purposes other than those for which the data was provided, and transferring it by the company, clients, or others to another person. A party, or shifting the blame to a third country, has a negative impact on companies, consumers, and users in terms of marketing, customer service, and employees. As for the solutions to this problem, they include: Secure mooring, which is following the principles agreed upon between the two parties.

\section{- Operating style}

The digital marketing process involves sending a message outlining the request according to the specifications provided by the company on its website. Then the company responds with the arrival notification, then takes the necessary measures to implement the request.

For the transaction to be executed reliably, the correspondence process must be conducted securely. However, some customers take a long time with the site and may delay the final decision by more than a day. This is why some traders set a time limit at which the process stops. Sometimes the request is sent, but the specified time runs before sending a notice from the company to the customer about the arrival of the message and taking the necessary actions to fulfill his request. Rather, in many cases, especially if the request is important to the consumer, the customer repeats his request and ends up meeting his desire twice and paying the price of two copies of the goods, and the program that performs the procedures may automatically cancel the order that was not completed on time. Perhaps the solution lies in designing the program to prevent such an error

\section{- The method of entering the site}

The sites that do digital marketing are divided into free sites and non-free sites, where the first service is provided to advertise, sell and buy goods and obtain all the site's information and services without financial compensation, while in the 
second the service or part of it is obtained only through material fees in the form of subscription Monthly, yearly, or otherwise. It should be noted that free sites obtain a reasonable amount of material revenue by publishing paid ads with special specifications that differ from free advertisements for goods in terms of location, size, width, and colors used. ${ }^{3}$

\section{Conclusion}

In a world dominated by the language of knowledge, technological progress has become the main engine of the global economy, and the development and prosperity of countries have become measured by the extent of their adoption of this technology, which made many countries of the world aware of the importance of this technology and strives to harness it to serve the entire economy, especially the commercial side. Interest in commerce dependent on an electronic medium is evidence of mature economic awareness. This trade, which was just a dream, imposed itself today in determining the economic future of countries, and became the main mode of commercial activity, as its volume grew at an incredible speed in various parts of the world, due to the many advantages it provides, especially reducing time and distances and reducing costs. Perhaps the experiences of some Arab countries, which are witnessing major transformations to move to the digital world, are the biggest incentive to encourage the Gulf Cooperation Council to absorb these tremendous technological changes, keep pace with the qualitative movement, and experiment with digital marketing. To take advantage of the advantages of its application and push towards its development and development to achieve economic prosperity in it. In addition, because of its many advantages.

\section{References}

- Al-Essawi, Ibrahim, Digital Marketing, Cairo: The Academic Library, 1423 AH. Mohsen Khoudary, Knowledge Economy, (Cairo: The Arab Nile Group, 2001)

\footnotetext{
${ }^{3}{ }^{3}$ Swinehart, T., Local e-Commerce Issues -Where ICANN's Jurisdiction Ends and e-Commerce Begins, Counsel for International Legal Affairs, The Internet Corporation for Assigned Names and Numbers (ICANN); (July 19, 2002).
} 
Jassim, Jaafar (2010: Introduction to Digital Economy, Amman: Dar Al-Bidaya Publishers and Distributors)

Ibrahim Al-Essawi, Digital Marketing, (Cairo: The Academic Library (Egyptian Joint Stock Company, 2003 AD))

Reynolds, J., The Complete E-Commerce Book: Design, Build, and Maintain a Successful Web-Based Business, CMP Books (April 2004).

Kessler, M., More Shoppers Proceed to Checkout Online, USA TODAY,

(December 22, 2003)

Nissanoff, D., Future Shop: How the New Auction Culture Will Revolutionize the Way We Buy, Sell and Get the Things We Really Want, Hardcover, 246 pages, The Penguin Press (2006).

Jones, D., (Foreword); Scott, M. and Villars, R., E-Commerce for Dummies, For Dummies (July 15, 2001).

SBA Office of Advocacy, E-Commerce Report, U.S.A. Small Business Administration; (July 1999).

Krishnamurthy, S., E-Commerce Management, Mason, Ohio: Thomson / SouthWestern (2003)

Burdett, D., RPC \& ecommerce, Commerce One; (January 25, 2000).

- IDC, Internet Usage Increasing Rapidly Across Southeast Europe, International Data Corporation, Framingham, MA (2002).

- Swinehart, T., Local e-Commerce Issues -Where ICANN's Jurisdiction Ends and e-Commerce Begins, Counsel for International Legal Affairs, The Internet Corporation for Assigned Names and Numbers (ICANN); (July 19, 2002).

Copyright (C) 2021 Dr. Ali Rashed Nasr, AJRSP. This is an open-access article distributed under the terms of the Creative Commons Attribution License (CC BY NC). DOI: doi.org/10.52132/Ajrsp.e.2021.243 